\title{
The Influence of Cryptocurrency on International Relations and Sanctions
}

\author{
Hvidson Kamala Khas
}

\begin{abstract}
This study is focused on the analysis and impact of cryptocurrencies on international relations and illicit activities along with the lawmakers' approach towards illicit activists and crimes that have picked up since the creation of Cryptocurrencies. The massive growth of cryptocurrencies can be noticed by seeing ATMs, wallet users, and businesses accepting Cryptocurrency. While this new technology is being developed, various authorities have been forced to set regulations, given the expansive growth of Cryptocurrency over the years. There are multiple terminologies used to describe Cryptocurrency from one jurisdiction to another. One of the most common actions identified across jurisdictions is the Government-issued notices issued to the Central Banks to regulate cryptocurrencies. These warnings issued by various countries majorly center around the fact that cryptocurrencies may create a root for illegal activities such as money laundering, terrorism, and other organized crimes. Cryptocurrencies are favorable due to their trade speed, cost, and security. The total market cap peaked at more than \$2 trillion on November 4th, 2021, with up to 7, 616 Cryptocurrencies, according to investing.com. There are instances where cybercriminals made hostages extort payment in terms of Cryptocurrencies. Most crowd funding is scams and takes away the money. There are claims that as soon as cryptocurrencies became popular and valuable, hackers and other criminals started to demand crypto instead of PayPal or Western Union. This high demand for crypto in the crime world emerged as a significant concern for bankers and governors, with criminals exploiting digital financial services to perpetrate money laundering and other types of crimes.
\end{abstract}

Keywords: Cryptocurrency, Economy, International Relations, Fraud, International Sanctions, Banking

\section{Introduction}

The world of the monetary system started to change in early 2008 when Bitcoin was introduced as a digital currency by Satoshi Nakamoto. Nakamoto launched this worthless currency for mining in 2009, and the first transaction was processed in 2010, two slices of pizza for 10, 000 Bitcoins in Florida, USA. As of 2021, Bitcoin covers most of the market as the mother of the coins and there have been many blockchains introduced with over 4,000 of coins and tokens in the market. Bitcoin has come over $\$ 682$ billion in market capacity and has reached a price break of $60 \mathrm{k}$ per coin. The rapid jump in the price of Bitcoin made it of great interest to investors worldwide. In addition to the drastic market value, the simplicity of trade through technology and electronic payments helped the popularity of digital currency investments [1].

These virtual currencies operate on a decentralized system, making it difficult to determine the user's identity and location. Considering the lack of detecting capability, this blockchains system offers a level of anonymity not seen in other laundering activities. This system is further complicated in that it is not possible to be audited and this freedom to transfer and make payments worldwide makes this channel attractive for money-launderers whose goal is to move and withdraw funds without any detection. Bitcoin does not use any central servers; it uses no servers and instead operates on a consensus network of computers internationally. The global network restricts access to users' information by involving thousands of computers to verify bitcoin transactions. The lack of central servers and the presence of cross-border payments utilizing a decentralized system that often segments transactions and originates from several different countries make it unwieldy for law enforcement to locate and access individual users. Without access to this information, there is no possible means to provide oversight to cryptocurrencies.
This decentralized system altered many lawmakers around the world as eluding regulations peaked up. Cryptocurrencies enable many violators to evade law enforcement and regulation limits in various manners, such as taxation and various illicit activities. In addition, these decentralized cryptocurrencies and their rapid value growth present a reasonable means for nations, corporations, and individuals to undermine economic sanctions imposed by the United States. Furthermore, to prevent this new upcoming instability in international relations and control of crimes, illicit activities, and political invasions, the world's commanders are looking into the United States enforcements on cryptocurrencies.

\section{Purpose of Study}

While the term "cryptocurrency" is relatively new in the world of finance, it has already had a significant impact on trading, investments, and monetary systems. Cryptocurrencies are now one of the most discussed topics in the past few years, and because of the essential factors and features, they will be regularly used in the future.compared to the traditional monetary system, cryptocurrencies are introducing new online security features, investment opportunities, and future careers to the new generations. With all that cryptocurrencies are bringing to the new monetary system and economy; society must study and research this technology.

This new technology will be providing a variety of careers such as blockchain developers, cryptocurrency developers, miners, analysts, software developers, and many other professions to the public. In addition to career development, blockchains technology influences various industries, and it can reduce operational costs and help eliminate cross-border payments.

Online security is another good reason to study blockchain and cryptocurrencies. Blockchains are introducing new 
digital safety standards, and this decentralized approach makes it one of the safest online payment methods. In addition, the blockchain system is entirely independent, selfregulated, and decentralized; thus, there is no need to involve a third party to process information manually.

Cryptocurrency projects have become popular, and increased is that blockchains bring a reasonable investment opportunity. When society studies cryptocurrencies and blockchains, they can start investing early, using their knowledge, and profiting from it. In addition, the cryptocurrency market is being gradually analyzed and regulated. These regulations will prevent illicit activities and frauds; thus, market volatility may not be an issue in the future. All this study and regulation will bring stability into the market, and traders will add another asset to their portfolios and diversify their investments.

With all security and features of cryptocurrencies, it is hard for governments and financial institutions to ignore this technology. As a result, the governments are increasingly interested in digital coins, looking for possible ways of regulation and institutionalization. Moreover, several countries, including China, Russia, Singapore, Sweden, and Japan, have already created their cryptocurrencies. Therefore, a brief understanding of cryptocurrencies and blockchain's features, advantages, and disadvantages becomes necessary. This study explores major research questions; What are blockchain and cryptocurrencies, and their economy today? What are different governments' approaches towards cryptocurrencies? How are the cryptocurrencies crimes rates changing? The study's overall design incorporates all the main topics discussed herein with a comprehensive review of existing literature to ascertain the core of the discussion.

\section{Cryptocurrencies in Today's Economy}

Nowadays, due to digitalization and improvement in tech, electronic payment systems are widely being used, and bitcoin adds some new features to these transactions, making this digital coin favorable and, meanwhile, debatable. After accomplishing this popularity, Bitcoin has been widely spoken to be accepted as a payment system. While this acceptance of digital currency has been introduced to the monetary system, many governments and lawmakers are trying to challenge this transition [2].

Bitcoin is a person-to-person coin; it is decentralized and can be traded simply through online blockchain platforms. Most importantly, any transactions through these blockchains are not backed, tracked, posted in any banking system, and will not be audited. These unique features and simplicity to trade without international policy enforcements have pinched the attention of the public and policymakers.governments have identified and practiced different enforced policies regarding blockchains. While many governments still have not announced any sort of critical enforcement on digital currency trading, there are some government-imposed limits on trades through the blockchains [3].

The enormous value growth and investments in cryptocurrencies has taken the world's attention. Before debating the impact of cryptocurrency on the economy, the relation between these two essential manners should be discussed. Numerous daily international trades are being processed through different currencies with different exchange rates. Sometimes trading with traditional currencies has some losses for traders due to floating exchange rates and transaction costs. While on the other hand, cryptocurrencies are almost free from taxation charges and have no transaction costs. While cryptocurrencies are still youthful, the impact of blockchains on the economy is a controversial debate between investors and economists [4].

Cryptocurrencies have various effects on the political, economic, cultural, and social life of humankind. Today, digital currencies are not becoming a substitute for traditional money. Still, they are replacing it with the new formation of funds, which governments cannot unseen. Moreover, since there is no strict regulations, guarantee, or backup to protect cryptocurrency buyers and traders, a massive risk is in ambush for buyers, and all trading carries risk. However, this does not change the fact that blockchain tech intends to change the financial system in the world. Yet, the financial world will change, shifting currencies to an electronic form of money. As of today, bank institutions and governments do not accept cryptocurrencies. They even set restrictions on them and limited all transactions from their debit and credit cards to block crypto resources. For decades, cash was the king for corruptions and lawbreakers, seeing that legal transactions are being mirrored or required to pay taxes. However, studies showed that eliminating cash usage can diminish criminal activities [5]. Moreover, Björn Eriksson, Swedish police chief, presented Sweden's success in fighting crime by reducing cash from circulation and moving to digital banking [6]. Additionally, Riksbank reports back up the idea of how much crime is linked to the usage of cash in Swedish society [7]. Contrary to other payment methods like deposit accounts, digital coins cannot be controlled or predicted by any other party except the sender and receiver. Accordingly, cryptocurrencies are the new kings for criminals since they replace cash and create new anonymous payment methods.

The creation and spreading of cryptocurrencies come with various risks and regulatory issues. Because of unpredictability and decentralization, they could facilitate crime and money laundering. Because cryptocurrencies grant an opportunity for cash flow among individuals without governmental or any third parties' participation and no border limitation, one can say that the amount of market demand sets the price of them. Yet, central banks have no power to control the market directly. Still, they can reduce the need by setting limitations and restrictions for their customers, which will result in reducing demand and the price eventually. Moreover, the battle between central banks and the crypto market has already started since cash-out crypto coins are banned in countries such as Egypt, Turkey, Algeria, Vietnam, and etc., and highly limited by many central banks such as Swedish and Indian's banks [8].

Based on what has been argued so far, one can say that since cryptocurrencies are decentralized and anonymous along with being independent of banks, governments, and 
governmental institutes, eliminating blockchain from public life cannot be seen as a favorable condition. However, as much as this is true, bank institutes can limit the usage of cryptocurrencies and dramatically affect their price by setting restrictions for their customers who trade in crypto. Thus, sooner or later, if the use of cryptocurrency enhances to a broader era, it may eliminate the ability of central banks to enforce and carry monetary policy, which leads economists to the question of whether central banks must develop their digital currencies or not. Authorities began regulating blockchain platforms after the high number of illicit activities across the world. While all governments have the goal of enforcing policy on blockchains platforms in common, they have different approaches towards this regulation. This different policy enforcement among the global authorities made cryptocurrencies a vague market for investors at the same time, an unstable platform for the international trade violators.

\section{The United States of America Regulations for Cryptocurrencies}

The surge in international cryptocurrency investment was started while the authorities did not have major control over cryptocurrency transactions. With increased studies of global policies bodies, many countries will look to the United States to regulate their cryptocurrency market. However, the United States' government agencies have varying policies across the federal entities, while cryptocurrencies laws vary from state to state. In addition, the U. S. has the second-largest volume of Bitcoin, nearly fourteen percent, and retrospectively set up no regulatory guidelines compared to other major powers. This lack of a uniform regulatory framework has not made the U. S. well suited to welcome the global adventure of cryptocurrencies.

Without a compact uniformed system of rules, many blockchain startups avoid the U. S. due to the implications of future taxations. This avoidance started in the United States; there are different political and economic approaches for cryptocurrencies among the states and federal governments. The various regulations among the U. S. states appear to be in contrast. Some states do not consider Cryptocurrency legal, while others have found a way to encourage Cryptocurrency and promote blockchains. Initially, Cryptocurrency was not a legal trade, but now, there are few exceptions. While the benefits of this technology are still cynical, several policymakers have acknowledged the regulation risk of the currency. In contrast, others have passed legislation to increase investment in technology. The United States Department of Treasury does not consider Cryptocurrency as legal. Since 2013, the network has deemed it a substitute for currency and considers it a money transmitter. In contrast, the Internal Revenue Service (IRS) counts Cryptocurrency as property and has declared tax guidance for the cash. In March 2014, the IRS announced that Bitcoin and any other cryptocurrency would be taxed as "property, " not currency. IRS explained further that every individual or group trading in Cryptocurrency should keep a record of cryptocurrency sales and purchases. In addition, they are entitled to pay taxes for the gains on every sale, purchase, and mined made through cryptocurrency platforms and mined cryptocurrencies [9].
State Regulation wise, the Wyoming legislature has exempted Cryptocurrency from property taxation. In addition, the state of Colorado passed a bill to require blockchains to keep track of transactions to provide for governmental purposes. Moreover, other states like Arizona and Georgia have started accepting taxes on a cryptocurrency exchange in November 2018. While some American states like New Mexico and California have issued warnings about cryptocurrency investment and New York has restricted the currency [10]. Regarding exchange, the trade regulations of Cryptocurrency are also considered as an uncertain legal territory. Only one regulatory body, Security and Exchange Commission (SEC), knows Cryptocurrency as a security measure. In March 2018, it declared that it would apply security law for digital wallets and exchanges. In contrast, the Commodities Future Trading Commission (CFTC) follows a friendly approach for bitcoin traders as it allows traders to trade publicly. Although there is no consistent legal approach for Cryptocurrency in the USA, cryptocurrencies are still under discussion in several American regions; many investors and large companies in the USA such as Tesla are taking a high interest in this investment [11].

\section{Canada Regulations for Cryptocurrencies}

Canada allows the use of Cryptocurrencies, although they are not considered as legal tender in Canada. The Consumer Agency of Canada announced that digital currencies could be exchanged to buy goods on the internet and stores that process cryptocurrencies aside from the regular cryptocurrency exchanges [12]. Canada's tax laws apply to digital currency transactions, and all digital currencies are subject to the Income Tax Act [13]. The Canada Revenue Agency (CRA) has characterized cryptocurrency as a commodity and not a government-issued currency. In addition, while filing taxes, any gains, or losses from selling or buying digital currencies must be reported [13].

The Canadian parliament legislation made Canada become the first country to approve cryptocurrency regulation in anti-money laundering as an Act to Implement Certain Provisions of the Budget Tabled. This legislation amends Canada's Proceeds of Crime (Money Laundering) and Terrorist Financing Act to include Canadian cryptocurrency exchange. Recently, the Ontario Securities Commission has been enforcing strict laws on one of the largest digital asset trading platforms, Binance. The legislation forces the platforms to comply with specific Canadian security legislation that requires additional registration. However, unlike the United States, Canada did not cause this registration first, entitled Binance authorities to update customers agreement that concerns crypto traders in Ontario [14].

\section{European Union Regulations for Cryptocurrencies}

Since January 2020, cryptocurrencies and blockchains became the European Union (EU) target after the Fifth Anti Money Laundering Directive. This act means that EU members and financial institutions consider trading in 
cryptocurrencies as a legal trade as long as traders meet standard reporting requirements ( $\mathrm{aml} / \mathrm{ctf}$ ). However, ultimately to this decision, members decided to enumerate cybercrime under the money laundry predicate offenses. Along with this new legislation, cryptocurrencies and blockchains are determined as qualified financial instruments. In addition to this law, no bank, institution, or company is prohibited from holding or trading crypto assets. As the European Union is actively seeking further legislation on cryptocurrencies, members are concerned about the risks bound with private digital currencies. As much as this is true, it is that central banks of EU members are exploring to issue their crypto and digital currencies [15].

Among all, Sweden, being the most cashless country globally, has decided to create its own digital currency, said Riks Bank. Cecilia Skingsley, the deputy governor of Sweden, claims that Sweden needs to be at the leading edge of creating a new payment system as the usage of cash is declining in Sweden faster compared with other countries. Skingsley also mentioned that "The less those of us living in Sweden use banknotes and coins, the clearer it becomes that the Riksbank needs to investigate whether we should issue electronic money as a complement to the money we have today" [16].

\section{Cryptocurrencies and Illicit Activities}

Over the last few decades, the United States has passed several acts to fight money laundry. Per the Money
Laundering Control Act of 1986, money laundering is a federal crime. Bank Secrecy 9 Act of 1970 has established the requirements for record-keeping and reporting to identify the volume, source, third parties involved, and the destination of transactions [17]. Customer Identification Program (CIP) is another set of regulations aimed at fighting money laundering by basically requiring due diligence from companies to identify their customers. The requirements of CIP to identify customers include collecting the name, date of birth, address, and identification number information from them [18].

Due to the anonymity of cryptocurrencies, many private entities and businesses use this system to transfer funds for personal purposes outside the reach of traditional banking systems. Thus, cryptocurrencies have become a haven for people and businesses to conceal their illegal activities such as gambling, selling counterfeit goods, selling child pornographic content, and etc. It is needless to mention that certain activities in order to burden the payable tax are differ from tax evasion; some well-known examples of that could be tax planning, tax saving, and tax avoidance. Nevertheless, one can say that the mentioned activities are considered as legal activities, contrary to international tax law, tax evasion is considered as fraud and illegal activity. In the context of tax fraud, most of the tax evasion cases which are implicated with cryptocurrency are intentional. Moreover, most usage of cryptocurrency in tax fraud is related to income tax [19].

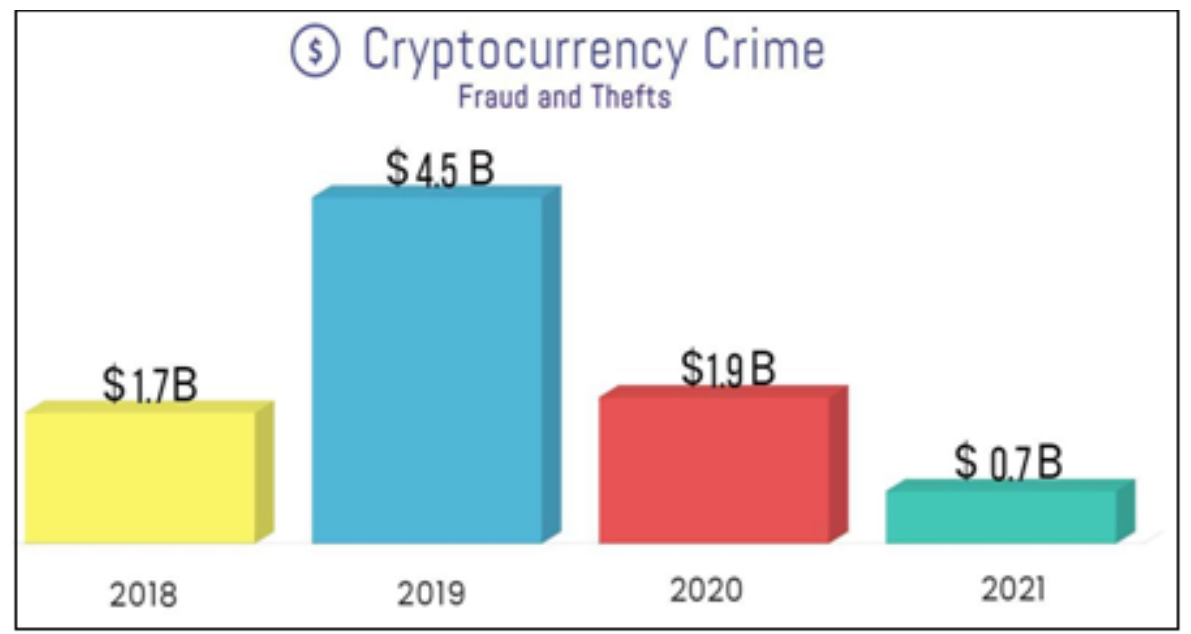

Figure 1: Blockchain Fraud and Thefts (Source: CipherTrace Cryptocurrency Intelligence)

According to CipherTrace's Cryptocurrency Crime and Anti-Money Laundering Report released in 2021, major crypto thefts, hacks, and frauds totaled $\$ 0.7$ billion in 2021 which has decreased by $\$ 1.2$ billion annual value in crypto crimes compare to 2020. Massive exit scams have dominated cryptocurrency crimes in the last four years. In 2019 , the fraud and thefts value reached $\$ 4.5$ billion which is the peak in cryptocurrency's crime and money laundering [20].

As the US attorney Chad Meacham claimed, "Transacting in virtual currencies does not exempt businesspeople from paying income taxes". Moreover, Christopher Altemus the special agent of IRS said that "As digital currencies continue to emerge as an investment option for taxpayers, we must continue to increase the pressure on anyone who tries to take advantage of their investors and taxpayers through fraud and tax evasion. The great work from both the Dallas and Los Angeles IRS-CI field offices firmly puts that pressure on these two cybercriminals and serves as a warning to others" [21]. One can say a legal way of tax avoidance and delaying tax payments in a legal manner is to hide the capital in governmental bonds, which gives the opportunity to the holder to not be required to pay tax on the capital if the bonds is held. As it seems, cryptocurrencies can be an alternative option for individuals and firms to hide their capital and avoid tax payments, however, the anonymity of crypto makes it impossible to determine or estimate the 
capital as soon as they turn it into crypto. Additionally, due to the anonymity of its transaction, one can transfer the capital and makes it not possible for the IRS to trace and evaluate the firm's or individual's total assets [19].

\section{Crypto-currencies and Financial Sanctions}

Financial sanctions are becoming a vital foreign policy tool by the world powers and an alternative way for an economic war instead of a military war. For the United States, the Treasury Department's Office of Foreign Asset Control or OFAC administers economic sanctions. OFAC was officially created in 1950 to respond to China entering the Korean War to block or freeze all Chinese and North Korean assets within U. S. jurisdiction [22]. The United States government has imposed financial sanctions against individuals and corporate entities in Russia, Myanmar, Nicaragua, Venezuela, North Korea, Cuba, and Iran. These economic sanctions target exports' prohibition, including minerals, oil, coal, iron, and agricultural products. Import sanctions include aviation fuel, oil, military equipment, transport vehicles, luxury goods, and communications equipment [23].

Sanctions have different sequences of impact on the financial revenue of the targeted firms and industries, and this impact extends to the country's political structure. To this end, we focus on sanctions imposed on Iranian corporations and how Iran has overcome this hardship since 1979 when the Society for Worldwide Interbank Financial Telecommunication (SWIFT) started banning some Iranian banks from accessing its widely used cross-border payment services. Many of these sanctions have been imposed in response to its nuclear and ballistic missiles programs. Due to the intensity of the length and diversity of the sanctions, Iran suspended much of its nuclear uranium enrichment efforts and resumed negotiation with the United States and five other world powers about its nuclear program [24].

The growing prevalence of virtual currency as a payment method brings more significant exposure to sanctions risks like the risk that an economically sanctioned person or country in an authorized jurisdiction might be involved in a virtual currency transaction. Due to the anonymity and ease of payment, many sanctioned countries took a step to use cryptocurrency to evade the global financial sanctions targeting their sanctioned trades transactions. Accordingly, the virtual currency industry is increasingly critical in preventing sanctioned persons and countries from exploiting virtual currencies. OFAC sanctions compliance requirements apply to the virtual currency industry in the same manner as they do to traditional financial institutions, and there are civil and criminal penalties for failing to comply [25]. The guidance issued by OFAC today provides an overview of OFAC sanctions requirements. In addition, it provides examples of compliance best practices for operators in this space, including technology companies, exchangers, administrators, miners, and wallet providers, as well as more traditional financial institutions that may have exposure to virtual currencies or their service providers. If ignored or mishandled, sanctions risks are vulnerabilities that can lead to violations and subsequent enforcement actions and harm U. S. foreign policy and national security interests [25].
The U. S. Department of the Treasury issued the first designation of virtual currency exchange for facilitating transactions for violators in October 2021. This announcement introduces additional steps that help the virtual currency industry prevent exploitation by sanctioned persons and other illicit actors. These actions are part of President Biden Administration's focused, integrated effort to counter the ransomware threat. The Department of the Treasury leads a collaborative approach to counter ransom ware attacks, including public-private partnerships and close relationships with international partners [26]. "Ransom ware actors are criminals who are enabled by gaps in compliance regimes across the global virtual currency ecosystem, " said Deputy Secretary of the Treasury Wally Adeyemo. "Treasury is helping to stop ransomware attacks by making it difficult for criminals to profit from their crimes, but we need partners in the private sector to help prevent this illicit activity. "said Deputy Secretary of the Treasury Wally Adeyemo [26].

\section{Summary and Conclusion}

In conclusion, the extent to which cryptocurrency regulation will parallel that of physical currencies remains uncertain. Cryptocurrencies are favorable due to their speed, cost, and the market capacity has rapidly reached more than $\$ 2$ trillion. Since this decentralized investing technology is becoming more popular and valuable, hackers and cybercriminals started to demand crypto instead. For this decentralization regulations should target cryptocurrencies and other intermediaries linking cryptocurrency and the real. These exchanges should be controlled by central authorities and can be the target of regulatory enforcement. The intangible nature of cryptocurrency does not fit neatly within any current. Cryptocurrency has many current and potential uses that regulators must consider. To address this issue, it is recommended that regulators look to cryptocurrency to consider specific regulations and anyone who intends to transact with cryptocurrency should therefore do so with the utmost caution. This will ensure the effectiveness of existing regulations is not undermined by the existence of unregulated cryptocurrency-based products and ensures regulations have considered the risks and specific concerns.

Lastly, to circumvent regulatory arbitrage and the undermining of a single country's regulatory efforts, it is recommended as a desirable outcome that regulations be consistently adopted as standards internationally. After all, some questions will remain unanswered since the world is unsure about the act and consequences of cryptocurrencies. For instance, Will monetary policies work as they do today? Will central banks have monetary policy power in the economy while blockchains take over the money? What if the world's most traded cryptocurrency went to zero? This paper shined a light on a relatively new topic. Further research needs to be conducted since some gaps remain questionable out of the spotlight. Further study on a global scale can be beneficial for both governmental institutes as well as private sectors. Moreover, this research has had a significant focus on money laundering, sanctions, tax evasion, and individual usage of cryptocurrency, however, more aspects of cryptocurrency such as international relations and security, must be studied through further 
research and the updated regulations on this broad field and technology of cryptocurrencies.

\section{References}

[1] Litwack, Seth. "Bitcoin: Currency or Fool's Gold: A Comparative Analysis of the Legal Classification of Bitcoin. " Temp. Int'1 \& Comp. LJ 29 (2015): 309.

[2] Agarwal S. Note: Bitcoin transactions: A bit of financial privacy. Cardozo Arts \& Entertainment Law Journal.2016; 35: 175.

[3] Hobson JE. Blockchain and Cryptocurrency-Two Road Converge. MULTISTATE TAX'N \& INCENTIVES.2018; 28: 40.

[4] Everett C. The Cryptocurrency Investing Guide: How to Invest and Trade Cryptocurrencies for BIG Profit. R\&C Publishing; 2018.

[5] Warwick D. Reducing Crime by Eliminating Cash. National Council on Crime and Delinquency, Davis, CA. Published online December 1993: 49. https://eric. ed.gov/?id=ED377114

[6] Eriksson B. KORTEN PA BORDET. kontantupproret. Published online 2014: 20. https://www.kontantupproret. se/wpcontent/uploads/2014/11/Korten. På. Bordet. print_.pdf

[7] Crimes linked to cash have fallen. Riksbank. Published November 7, 2019. https://www.riksbank. se/en- gb/payments--cash/payments-insweden/payments-in-sweden-2019/swedish-

payments-are-secure-and-efficient/security-insweden-is-high-from-an-internationalperspective/crimes-linked-to-cash-have-fallen/

[8] Nokleholm, Beate Adelaida, and Gina Vangen Kviseth. Regulation of Cryptocurrency: An Analysis of the Proposed Markets in Crypto-Assets Regulation Emphasizing on the Issuer of Stablecoin. MS thesis. Handelshøyskolen BI, 2021.

[9] Co NO. Regulation of Cryptocurrency in Various Jurisdiction across the World. SSRN Electronic Journal. Published online May 7, 2021: 10. doi: 10.2139/ssrn.3841589

[10] Goforth CR. U. S. Law: Crypto is Money, Property, a Commodity, and a Security, all at the Same Time. Journal of Financial Transformation, Forthcoming. Published online November 16, 2018: 11.

[11] Goforth, Carol R. "US law: Crypto is money, property, a commodity, and a security, all at the same time. " Journal of Financial Transformation, forthcoming (2018).

[12] Yadav, Aman. "Cryptocurrency in India: to Ban or not to Ban. " Aman Kumar Yadav, 'Cryptocurrency in India: To ban or not to ban' (The RMLNLU Law Review Blog, 2 March 2021), available at: https://rmlnlulawreview.com/2021/03/02/cryptocurre ncy-in-india-to-ban-or-not-to-ban (2021).

[13] Cumming, Douglas J., Sofia Johan, and Anshum Pant. "Regulation of the crypto-economy: Managing risks, challenges, and regulatory uncertainty. Journal of Risk and Financial Management 12.3 (2019): 126.

[14] Bill C-31, An Act to Implement Certain Provisions of the Budget Tabled in Parliament on February 11,
2014 and Other Measures, Second Session, Forty-first Parliament, 62-63 Elizabeth II, 2013-2014, Statutes of Canada 2014 Ch.20,

[15] EUR-Lex-52020PC0593-EN-EUR-Lex. Europa. eu. Published September 2020. https://eur-lex. europa. eu/legalcontent/EN/TXT/?uri=CELEX\%3A52020PC0593

[16] Duxbury C. Sweden's Central Bank Considers Digital Currency; Deputy governor says nation's sharp decline in cash usage may make it among first to adopt new system. Wall Street Journal. Published online December 2016. https://www.proquest.com/docview/1839606589?pqorigsite $=$ primo $\&$ accountid $=11754$

[17] Yalaman, Gamze Öz, and Hakan Yıldırım. "Cryptocurrency and Tax Regulation: Global Challenges for Tax Administration. " Blockchain Economics and Financial Market Innovation. Springer, Cham, 2019.407-422.

[18] "Customer Identification Program-Overview." FDIC: Federal Deposit Insurance Corporation, 24 Aug.2007, p.47

www.fdic.gov/regulations/examinations/bsa/ffiec_cip. pdf.

[19] Babcak V, Romanova A, Vojnikova I. The use of cryptocurrencies for tax evasion and tax fraud. University of Wroclaw.2015; 2: 253-263. https://www.researchgate.

net/publication/301200553_The_use_of_cryptocurren cies_for_tax_evasion_and_tax_fraud

[20] Campbell-Verduyn, Malcolm. "Bitcoin, crypto-coins, and global anti-money laundering governance. " Crime, Law and Social Change 69.2 (2018): 283-305.

[21] Founders of Crypto ICO Plead Guilty to Tax Evasion After Raising \$24 Million from Investors. www.justice.gov. Published October 12, 2021. Accessed November 2, 2021. https://www.justice.gov/usao- ndtx/pr/founderscrypto-ico-plead-guilty-tax-evasion-after-raising-24million-investors

[22] "Basic Information on OFAC and Sanctions. " N. p., n. d. Web.9 Nov.2021 <https://home. treasury.gov/policy-issues/financialsanctions/faqs/topic/1501>.

[23] Borszik, Oliver. "International sanctions against Iran and Tehran's responses: political effects on the targeted regime. " Contemporary politics 22.1 (2016): 20-39.

[24] Alfoneh, A. (2010): "The Revolutionary Guards' Looting of Iran's Economy," Discussion paper, American Enterprise Institute.

[25] Clautice, Thomas, "Nation State Involvement in Cryptocurrency and the Impact to Economic Sanctions" (2019). Economic Crime Forensics Capstones.43.

[26] Scoular, Jesse. Cryptocurrency: Illicit Uses, Legislation, Regulation, and the Burden on Law Enforcement. Diss. Utica College, 2021. 